\title{
LA SITUACIÓN ACTUAL DEL PSICOANÁLISIS
}

\author{
René MAJOR \\ Universidad de la Sorbona \\ (Traducción de Paco Vidarte)
}

Desde su nacimiento a comienzos del siglo veinte, se viene debatiendo de forma periódica acerca del psicoanálisis y sus «estados»: acerca del devenir de su práctica, la evolución de su teoría, acerca de la extensión del campo de un saber que el propio psicoanálisis ha inaugurado, así como sobre la expansión del movimiento que asegura su transmisión. Ya se considere al psicoanálisis como una ciencia interrogándonos acerca de su singular estatuto, ya sea que le concedamos el rango de un arte de la interlocución con virtudes oraculares, un retorno reflexivo a la autoobservación, constitutiva de su método, permanece inherente a su andadura. Lo mismo ocurre con su historia, la cual no podría aparecer como "analítica", hablando con propiedad, sin tener en cuenta las reorganizaciones sucesivas - así como las traducciones reactualizadas- que los discursos teóricos llevan a cabo a lo largo del tiempo haciéndose tributarios de las interpretaciones de la memoria y, por añadidura, del lenguaje y del pensamiento de una época. En el interior de la disciplina misma, los hombres, abiertos a los avances que les son contemporáneos en el campo de las ciencias de la naturaleza o de las ciencias del espíritu, habrán impregnado fuertemente la lengua en la que serán pensadas, de modo efímero o duradero, las manifestaciones y los acontecimientos de la vida psíquica inconsciente. No obstante, los hechos objetivos que tratarán de establecerse a partir de observaciones singulares, no escaparán a la constante contrastación de sus fuentes y, llegado el caso, a la puesta en evidencia de la ciega tarea en torno a la cual se forman.

A propósito de este retorno a los orígenes de la disciplina y del modo en que ésta se ha constituido y desarrollado, el fundador del psicoanálisis ha dado ejemplos en varias ocasiones de lo que una investigación así puede suscitar. Es 
cierto que, para Freud, los descubrimientos del psicoanálisis y la historia de su teoría tienden a confundirse con su propio destino. Su «Contribución a la historia del movimiento psicoanalíticon previene de entrada al lector del carácter subjetivo de su exposición, ya que el psicoanálisis es su propia creación: "Durante diez años he sido el único personalmente interesado en él y todo el descontento que su novedad ha provocado entre mis coetáneos no ha hecho sino repercutir en $\mathrm{mi}$ en forma de críticas dirigidas a mi personaw. Así Freud se considerará justificado de tenerse por mucho tiempo como el más apto para decir lo que es realmente el psicoanálisis y como el mejor situado para deslindarlo de otros métodos o doctrinas que, reclamándose psicoanalíticas, mejor harían llevando otro nombre. Dicha "contribución" examina ampliamente las proposiciones teóricas de Jung y Adler, no tanto para mostrar su desvío del dogma, cuanto para escrutar los elementos sobre los que se fundan, delimitando las críticas que se le pueden hacer al autor y aquéllas a las que él mismo somete sus descubrimientos. La reinterpretación hecha por Jung de los hechos observados y analizados en términos abstractos y ahistóricos pretende establecer la economía de la sexualidad infantil y del complejo de Edipo. La que hace Adler, y que quiere vincular todos los resortes del psiquismo a la sola "protesta masculina" y la aspiración al poder, rechaza la importancia de la sexualidad y de la represión, excluyendo toda distinción entre los actos inconscientes y los conscientes.

En lo referente a la cuestión de la "cientificidad" del psicoanálisis, que se encuentra en el centro de los debates actuales, es la idea del descentramiento de la consciencia y del sujeto dividido la que sería rechazada de aquí en adelante, al mismo tiempo que la realidad sexual del inconsciente. Freud consiguió que las teorías de Jung y de Adler adoptaran otro nombre. La primera recibió la apelación de "psicología analítica" y la segunda la de "psicología individual». Setenta y cinco años más tarde, prácticas muy diversas se encuentran a su vez designadas con el nombre de psicoanálisis. Reclamando el nombre de Freud y la fidelidad a su pensamiento o preconizando una cierta emancipación en la prolongación de su obra, cada una de las teorías capaces de dar razón de la experiencia, se alza con una pretensión, explícita o implícita, de ser la única legítima. Esto es lo que, tal vez, les da a las escuelas de psicoanálisis, cuyas apuestas son tan múltiples, un aire de capillas. Sin embargo, cada una de las vías abiertas en el progreso de nuestro conocimiento del psiquismo traspasa hoy día más fácilmente las fronteras de las escuelas, las barreras de las lenguas o los límites del territorio nacional. 
Del mismo modo, desde el momento en el que estuviéramos autorizados a preguntarnos qué parte hay de método y qué parte hay de doctrina en la teoría analítica, nos vemos conducidos, en el mismo movimiento, a considerar los distintos avances actuales del psicoanálisis como profundizaciones en el interior del campo que éste delimita o como exploraciones en los confines de dicho campo, donde se tropieza con otras disciplinas como la linguística, las matemáticas, la física y la biología pero también la sociología, el derecho y la filosofía. Así, si aceptamos con Freud que, "tras haber designado en su origen un procedimiento terapéutico específicom, el nombre del psicoanálisis ha pasado a ser el "de una ciencia, la de lo psíquico inconsciente», el deseo, expresado por su fundador en 1925, de que esta disciplina «haga importantes contribuciones a los más diversos campos del saber", estaría en vías de realizarse. Si es verdad que podemos sorprendernos por que una ciencia se halle tan íntimamente ligada al nombre de su fundador -es un ejemplo sin precedente, como ha hecho notar Jacques Derrida - la novedad y la amplitud de la obra de Freud, la práctica que ésta ha inaugurado y la extensión de su campo dejan a sus sucesores inmediatos un ámbito tan vasto de reflexión que éstos ya no pueden aparecer como innovadores, sea cual sea la importancia de sus contribuciones.

Para Freud, el psicoanálisis tiene en efecto un contenido empírico y no se privó de modificar la teoría cuando estimaba que se hallaba refutada por la observación. En este sentido, las adquisiciones de una disciplina así son provisionales y sus resultados refutables, contrariamente a lo que Karl Popper quiere creer. Y es por referencia a esta "refutabilidad» por lo que Freud podía inscribir al psicoanálisis en el campo de las ciencias de la naturaleza: «No supone ninguna incongruencia que, lo mismo que en física o en química, los conceptos más generales carezcan de claridad y que sus postulados sean provisionales. Las definiciones más precisas se vinculan a los resultados de trabajos futuros" (1922). Nuevos conocimientos en biología, por ejemplo, podrían suponer una revisión de la teoría de las pulsiones. "En diversos ámbitos todavía no hemos superado la fase de investigación, fase en la cual se ensayan diversas hipótesis, las cuales se ve uno obligado muy pronto a rechazar por inadecuadas. Pero, en otros ámbitos, tenemos ya un núcleo de conocimientos seguros y casi inmutables» (1927). Dentro de estos últimos se afirman, en efecto, como irrefutables, los procesos psíquicos inconscientes, la sexualidad infantil y su inserción en la estructura edípica, la resistencia y la represión. Son éstos datos del campo subjetivo que se han constituido luego en objetividades. No sucede lo mismo con la disparidad subjetiva de la transferencia, que sin embargo es central en la expe- 
riencia analítica, pero que permanece a la espera de una teoría. Y el arte de la interpretación (Deutungskunst), que pone en juego al inconsciente del analista, al hacer posible la inversión de los signos, deja que el deslinde de los campos de lo subjetivo y de lo objetivo permanezca inestable. Un saber inconsciente viene a distinguirse aquil de un saber sobre lo inconsciente sin que sus jurisdicciones respectivas sean fácilmente delimitables. Por otra parte, cuando se entrega a la especulación, como sucede con la teoría de las pulsiones, Freud debe recurrir a préstamos de lo que llama «los pensamientos del lenguaje» (Sprachgedanken) para paliar la carencia de datos empíricos. Por esta vertiente especulativa, el psicoanálisis desemboca en las ciencias del espíritu (Geisteswissenschaften). De tal forma que, situada en la intersección de las ciencias de la naturaleza y de las ciencias del espíritu, pone en cuestión las jurisdicciones que éstas se atribuyen así como las que delimitarían un sujeto de la ciencia distinto de un sujeto del inconsciente. El psicoanálisis hace aparecer, en el borde exterior del campo que él mismo debe circunscribir provisionalmente, el condicionamiento por el inconsciente de los discursos científicos y la determinación de sus formas de pensamiento por el lenguaje de una sociedad o de una época. En su borde interno, se ve confrontado con la partición del conocimiento adquirido subjetivamente por la transferencia con aquel otro que nace de la constitución de las objetividades y aquél que lo lleva a la especulación, necesaria por un tiempo. Al hacer esto, aporta también el motivo crítico del paso de un tipo de discurso a otro, de la lógica inconsciente a la racionalidad "científica", de las limitaciones de un tipo a otro y del límite impuesto a la traducción de nuestras deducciones por el lenguaje de las percepciones al que aquéllas deben recurrir.

De ahí se deriva una de las cuestiones actuales más cruciales que permite medir las evoluciones de la práctica, de la teoría y de la institución analíticas y se apoya sobre la separación entre las condiciones de transmisibilidad fundadas en la transferencia y la cientificidad del discurso encargado de asegurar la transmisión de un saber. Ya que es, desde luego, en torno al asunto de la transmisibilidad donde aparece la enjundia epistemológica fundamental vinculada al estatuto de la teoría analítica. Los debates más recientes han formulado esta cuestión en los términos contemporáneos de una teoría del conocimiento nacida del positivismo lógico. Con ello se habrá superado la paradoja según la cual el discurso del psicoanálisis, al hablar del inconsciente de un sujeto dividido, no puede, si persigue su objeto, sino producir enunciados que no excluyen el sujeto de la enunciación, con el riesgo de no aplicarse a sí mismo la división de la que habla. Si lo consigue, es por referirse a una teoría del conoci- 
miento que incluira la posibilidad de una verdad dividida. Ahora bien, esto es contrario a los criterios habituales de la ciencia, según los cuales el sujeto no enuncia lo universal más que excluyéndose a sí mismo. La legítima preocupación de separar la práctica analítica de las manifestaciones oscurantistas, reducidas a un poder oculto que se transmitiría secretamente, y de referirse, para ello, a un procedimiento de transmisión capaz de universalización, no debe hacernos perder de vista que el principio de la objetividad de la ciencia se halla confortado por una neutralización ilusoria de la división del sujeto y que, desde los teoremas de limitación de Gödel, todo sistema formal contiene una fórmula, al menos, que permanece indecidible. Un sistema así, por muy consistente que sea, no puede tampoco hoy día aportar la demostración de su propia consistencia. $\mathrm{Si}$, por tanto, el psicoanálisis no puede conseguir validar el conocimiento que expresa en los términos de un racionalismo positivista haciendo caso omiso de la división subjetiva, como contrapartida, le plantea a la reflexión epistemológica un desafio sin precedente: el de un discurso donde el sujeto debe poder enunciar lo universal sin encontrarse excluido y que no puede enunciar nada de ello si se excluye.

\section{Una axiomática paradójica}

Podemos hacernos una idea bastante precisa de esta axiomática paradójica a partir del cuento de Poe, La carta robada, que ha servido y aún sirve, desde 1955, de referencia tanto a la crítica de una lectura hermenéutica ingenua, como al establecimiento de una lógica del significante y de una problemática de la verdad en el campo psicoanalítico. Una pieza literaria semejante, a la que vienen a unirse otras (como La muerte y la brújula de J.L. Borges o Ciudad de cristal de P. Auster), encierra un sistema de conocimientos precisos y rigurosos — sin duda, sobre todo, presentidos- que no resulta impensable poner de relieve y formalizar. Pero la estructura del cuento es tal que ninguna posición de dominio es posible. El comentador que se aventura en el texto padece necesariamente sus leyes. De forma que toda exclusión neutralizadora del intérprete le hace ocupar la posición de uno u otro de los protagonistas. La lectura no puede, por consiguiente, sino redoblar la estructura narrativa y el lector no hace sino redoblar cada uno de los personajes. La carta, que siempre es sustituida por otra, siempre es una carta interceptada en un trayecto que podemos reconstituir hipotéticamente a partir de cada emisario. 
Se ha podido mostrar que la lectura esclarecedora que hizo Jacques Lacan de este cuento en su Seminario se ordena no obstante en torno al recorte de tres escenas donde la posición subjetiva, vinculada al deseo de hacer volver a sí la carta freudiana, implica a su comentador en la realidad político-institucional del legado de un pensamiento y de un pensamiento de la delegación, de tal modo que se anudan lo imaginario de la teoría que piensa regir a la práctica analítica y lo simbólico de la práctica que cree controlar a la teoría. La imbricación de una escena de herencia, de una escena analítica y de una escena especulativa - su puesta en espejo- se refleja en las múltiples reduplicaciones de los teoremas, ciertamente no personales sino singulares, que asedian la constitución de las objetividades teóricas. Los significantes que sujetan al sujeto de la enunciación tejen asimismo los enunciados que pretenden de algún modo decir lo verdadero o lo universal. Esto no impide que, de una lectura y de una interpretación así, que no se sostienen sin requerir de continuo nuevos suplementos, se desprendan conocimientos concernientes a los fenómenos de la vida inconsciente que sean no menos rigurosos que los atribuidos a la positividad científica, incluso si, en razón de la complejidad introducida por la parte inevacuable de subjetividad y de los índices del lenguaje en la "cientificidad" de sus enunciados, su transmisibilidad permanece más aleatoria aún.

Mientras esperamos que se llegue a delimitar mejor la especificidad del discurso por el que el psicoanálisis da cuenta de su objeto, ¿̨no podemos pensar que éste procede al modo de una ciencia conjetural, formulando, a partir de índices convergentes, hipótesis ciertamente sujetas a revisión pero capaces, al cabo de un tiempo, de esclarecer un conjunto de hechos observados? El psicoanálisis supone que esas convergencias no son fruto de la pura contingencia. Si nos referimos a la alegoría de $L a$ carta robada para atribuirle un rigor a la interpretación analltica, nos daremos cuenta de que la convicción de Dupin no se funda, como se cree habitualmente, en el hecho, por muy ingenioso que sea, de que el mejor modo de esconder la carta sería dejarla completamente a la vista. Ni siquiera en el hecho de que su localización vendría a estar dada por la metáfora de la chimenea y de sus jambas, ayuda mediante la cual un hermeneuta algo atento se daría cuenta de que la carta no se puede hallar más que allí, en ese gran cuerpo de mujer, donde el significante fálico falta de su lugar. El prefecto la ha descrito: la carta lleva un pequeño sello rojo, la marca del duque de $S$., y lo escrito muestra una escritura audaz y masculina. Ahora bien, si la carta que Dupin descubre lleva, al contrario, un gran sello negro, la marca de D. y una escritura menuda y femenina, y si estos signos comportan no obstante la certeza de que esconden la 
carta que él está buscando, es porque Dupin puede interpretar su inversión. Nada podía servir mejor las intenciones del ministro que desplegar y replegar en el sentido inverso, utilizando los mismos pliegues, la carta del duque a la reina para hacer de ella, en su devolución, la carta que le es dirigida por una mujer que posee su marca y que ha sido desviada de Dupin por su hermano. La implicación del intérprete se pone aquí al servicio de una rigurosa deducción lógica.

\section{Prácticas y teorías}

Dada la preocupación por constituir el psicoanálisis en un cuerpo de conocimiento cuya teoría pudiera transmitirse, una primera diferencia separa a los autores anglosajones, en general, de los autores franceses. Los primeros parecen ante todo preocupados exclusivamente por la formalización de la teoría analítica con vistas a hacerla aceptable "científicamente». Sin embargo, su orientación pragmática los conduce a considerar los problemas planteados por la transmisión de esta teoría a través de los enunciados interpretativos inherentes a la cura. Los últimos, siguiendo el impulso de Lacan, no contemplan la transmisión analítica más que bajo el fundamento de la transferencia. El lugar teórico concedido al "matema" abarca la totalidad de la transmisibilidad, pero esta totalidad no se confunde en absoluto con la de la formalización. Si, por esta distinción última, se desea tener en cuenta lo subjetivo en la objetividad, no es para nada seguro que un algoritmo formal pueda expresar adecuadamente algo del discurso analítico, el cual pretende esencialmente mostrar la función estructural del fantasma en la relación entre el sujeto y el objeto del deseo. Tampoco es cierto que la validez operativa de estos algoritmos en el campo "científico" sea epistemológicamente homologable en el campo analítico. Por último, estos procedimientos suponen como algo ya dado la validez del discurso analítico que precisamente quieren demostrar.

Para proceder al examen de otras diferencias es indispensable revisar, aunque sea brevemente, los derroteros por los que han discurrido las investigaciones en los Estados Unidos en estos últimos decenios. Sólo podremos tratar las más señaladas. Sería también interesante examinar - lo que no podemos hacer aquí - en qué medida estas nuevas orientaciones no son independientes de las circunstancias históricas y políticas, ya que los líderes de las escuelas o los nuevos teóricos -como Hartmann, Loewenstein, Rapaport, Erikson, Gill, Kohut - emigraron casi todos de Europa a raíz de la Segunda Guerra mundial. 
Se debe, por otra parte, ciertamente al impulso, venido de la clínica, que han representado los estudios referentes a la psicosis y al análisis de niños, el hecho de que al éxito de la Ego Psychology le haya sucedido, en favor del interés por el tratamiento de los estados graves hasta entonces considerados inaccesibles para el psicoanálisis -como el autismo o los "estados límites" entre la neurosis y la psicosis_, el triunfo de la Self Psychology, que ha tomado en cuenta los importantes problemas planteados por la cuestión del narcisismo en la transferencia. Con todo, esta noción de Selfque recubre en parte, pero en un registro conceptual completamente diferente, la noción de sujeto, toma prestados de una cierta filosofia y de una cierta sociología la idea de la representación que el sujeto se hace de sí mismo (de su cuerpo y de su espíritu), sin poner en cuestión la noción tradicional de sujeto, mientras que el sujeto lacaniano -interpretación del sujeto freudiano- subvierte (con Heidegger) lo que se suele llamar la filosofia del sujeto. Para los defensores de la Ego Psychology que ya utilizaban la noción de Self, el sujeto designa el conjunto de las instancias freudianas: el yo, el ello y el superyo. Y, si el narcisismo representaba para Freud un retraimiento de la investidura objetal y su reorientación hacia el yo, para Heinz Hartmann, Kris y Loewenstein, esa reorientación de la investidura recae sobre el Self. Este último representa al individuo real, del que los autores se esforzarán en concebir una parte, el yo, como susceptible de ser desgajada de los conflictos psicosexuales y satisfacer, de modo autónomo, una función adaptativa. Lacan ha forzado la caricatura de esta concepción asimilándola a la ideología de la adaptación del american way of life. Lo que se consigue con esto es una inflexión de la teoría freudiana en el sentido de una teoría de la intersubjetividad y compromete al discurso analítico en los senderos de una "dialógica". Lacan se dio cuenta rápidamente de que, por muy sofisticada que sea una concepción intersubjetiva de la relación analítica - tentación teórica a la que él mismo sucumbió durante un tiempo- no podría dar cuenta adecuadamente de la transferencia y de que la palabra interlocutiva está lejos de agotarse en el apóstrofe que se le dirigiría al analista. Una concepción semejante, imbuida del espíritu pedagógico o médico, no puede sino hacer problemático el fin del análisis vinculándolo con la identificación del analizado con su analista. Sabemos, sin embargo, que en este ámbito, incluso una teoría que parece dar cuenta mejor de los fenómenos no constituye una garantía de que no se pervierta en la práctica. Ahí se delinea una aporía del método analítico, porque, suponiendo que se tenga una teoría que pueda dar cuenta exhaustivamente de la práctica y que sea capaz de predecir el desarrollo de una cura, con ello ya no se produciría ningún efecto propiamente "analítico". 
Otra diferencia surge a partir de las nociones de sujeto y de intersubjetividad. Esta diferencia no se limita pura y simplemente a unas regiones geográficas, pero los autores americanos permanecen por lo general insensibles a lo que puede suponer la distinción entre un otro y el Otro - siendo el primero el doble del sujeto en el que se reconocen las identificaciones imaginarias y el segundo «el lugar donde se constituye el yo que habla con aquel que escucha». Si el analizante habla a un otro - un otro que el analista puede hacer presente descargando su presencia de las resistencias al inconsciente del discurso- su palabra se dirige, en cambio, al Otro radicalmente diferente. Hecho que el analista no debería olvidar si no quiere caer en el riesgo de reducir la relación (de no-relación) analítica a un two ego analysis, por no decir a una conversación banal. El sujeto no es más que aquello de lo que se ocupan las palabras y no aparece sino de manera fugitiva, mientras que los Self se pasan constantemente el espejo. Estas distinciones son importantes para el mantenimiento de una instancia simbólica en la situación analítica, la cual se vería conducida de otro modo a ser una relación puramente especular, incluso si se intenta marcar en ella la disimetría. El positivismo de buen gusto trans-Atlántico tendería a querer construir una lógica de la comunicación hecha de un lenguaje-signo implicando una sutura de la división del sujeto y consagrando a éste a una búsqueda del sentido del sentido. Esta es la razón por la que esta tendencia se apoya más bien en una filosofía hermenéutica.

Por último, ya se trate de los teóricos de la Ego Psychology, de los defensores de la Self Psychology o incluso de los adeptos a la teoría de Melanie Klein, su pensamiento común no se desvincula de una concepción diacrónica del desarrollo de la libido y se caracteriza, en formas diversas, por los estadios que seguiría, o a los que se fijaría, la organización de la vida psíquica. Es cierto que la teoría freudiana y la observación del niño pueden prestarse a una especie de objetivación de los estadios de desarrollo, del que es testigo la descripción de las fases oral, anal o fálica, pero el concepto de castración vinculado con la fase fálica y con el complejo de Edipo es también para Freud lo que estructura, interpretándola, toda pérdida (¿anterior?) de objeto. Esta última concepción, bajo la influencia del pensamiento de Claude Lévi-Strauss en antropología y la de Ferdinand de Saussure en lingüística, llegará a ser predominante en la teoría lacaniana con la supremacía concedida al registro simbólico, con el primado del significante en los efectos de la significación, con la contemporaneidad de la ley y del deseo, con la referencia a la metáfora paterna en la relación madre-hijo. Aunque el interés de Lacan por el punto de vista genético no siem- 
pre haya estado ausente - -el "estadio del espejo" se encuentra en el origen de su concepción del sujeto, la trilogía que persiste a lo largo de toda su obra (lo simbólico, lo real y lo imaginario) vincula más bien su pensamiento, al menos en un momento de su evolución, a la corriente estructuralista. El recentramiento de la teoría de la libido en torno a la fase fálica y al complejo de castración, la importancia concedida al lenguaje van de la mano con el lugar central de la figura del padre en la teoría freudiana. Incluso la causa de la psicosis la buscará Lacan no tanto en la relación madre-hijo como tal, cuanto en la forclusión de la metáfora paterna. (Incidentalmente, de la referencia primordial al padre tal como se da en Freud, el interés se desplazará, en la historia reciente de la teoría, hacia la referencia que se hace a la madre, tanto con Melanie Klein — la "buena" y la "mala" madre - como con Donald W. Winnicot - la madre "suficientemente buena"—, luego, hacia la referencia al niño, a quien se le supone capaz desde las primeras semanas, según Françoise Dolto, de comprender todo lo que se le dice y, en última instancia, al bebé, que ve, entiende e interpreta las angustias de la madre).

La teoría de Margaret Mahler tiene lugar en el seno de la teoría general del desarrollo funcional del yo defendida por Anna Freud. Conocida con el calificativo de "psicología del desarrollo", esta teoría se esfuerza en describir las tres fases en la relación simbiótica entre la madre y el nińo: el autismo normal, la simbiosis propiamente dicha y la separación-individuación. El recién nacido prolongaría el estado fetal no distinguiendo lo que viene de afuera de lo que percibe desde el interior. La madre sería percibida por el bebé como una parte de sí mismo sobre la que mantendría su omnipotencia hasta el año y medio, aceptando luego progresivamente la separación.

Retomando los puntos de vista de M. Mahler sobre el desarrollo precoz del niño y reformulándolos completamente en términos de narcisismo, Heinz Kohut construyó en los años setenta una teoría que contará con la aceptación de numerosos clínicos americanos. El sentimiento "oceánico", tan caro a Romain Rolland, que sería un vestigio del estado prenatal, constituiría el punto de retorno feliz al que remite la dolorosa separación. Del Self simbiótico procederían entonces dos instancias: el Selfgrandioso, cuya marcada omnipotencia se enraiza en la imagen del cuerpo y la imagen parental idealizada que soporta una instancia mixta — de síy del otro, diriamos aproximativamenteque Kohut llama SelfObject. Esta última noción se hace necesaria para el autor por el hecho de que considera - a diferencia de Freud, para quien la libido narcisista se transforma en libido objetal- que dos corrientes de energía psí- 
quica separadas invisten paralelamente el yo y el objeto. El «objeto-yo", si se nos permite la traducción, conservaría una existencia propia, mientras que, para Winnicot, permanece como un objeto transicional. Podemos preguntarnos si la división del sujeto no llega a objetivarse en Kohut en un clivaje entre el registro narcisista y el registro objetal, pero esta concepción, si pretende dar cuenta de problemas narcisistas importantes, conduce a una neutralización de las pulsiones y a descartar la teoría freudiana de la libido. Que ciertas descripciones clínicas de la "transferencia en espejo" o de la "transferencia idealizante" puedan corresponderse con lo que observamos cuando el analista -en cuanto otro- se encuentra investido de modo privilegiado como objeto narcisista, es una dimensión constantemente presente en la experiencia analítica, pero acentuar su importancia conlleva el riesgo de dejar en la sombra su componente agresivo, su aspecto ambivalente y su naturaleza conflictiva. Por otra parte, este si-objeto del que habla la Self Psychology debe a fin de cuentas contribuir, por la "confianza en sín y "el respeto de sí» a la autonomía del yo y, para decirlo todo, a la adaptación a una sociedad donde la cultura del narcisismo se presenta como un síntoma eminente.

Entre los trabajos consagrados al estudio de la sociedad a los que el psicoanálisis contribuyó en gran medida, es preciso citar los de la Escuela de Frankfurt. El Instituto de Investigaciones Sociales que elabora una "teoría crítica" y que es conocido por sus principales jefes de filas (Theodor W. Adorno, Max Horkheimer, Jürgen Habermas) estuvo desde muy pronto vinculado al Instituto Psicoanalítico de Frankfurt. Erich Fromm fue una importante figura de este último y su estudio sobre Psicoanálisis y política anticipó numerosos trabajos que no se retomaron sino después de la guerra y la vuelta a Alemania de los principales teóricos exiliados. Es en la revista Psyché, fundada por Alexander Mitscherlich, donde se vuelven a encontrar hoy, en la pluma de los Lorenzer, Dahmer, Cremerius, Rosenkötter los ensayos más contestatarios de la ideología liberal y las reflexiones más audaces sobre los efectos del nazismo a largo plazo. Mitscherlich tuvo la valentía de analizar la represión colectiva de los recuerdos del Tercer Reich y de criticar la brutal represión de aquellos que, en los años setenta, lucharon contra el famoso "consenso" político, social y cultural. Debemos a sus sucesores el haber exhumado la historia del psicoanálisis en el transcurso de los "años marrones». Frente a la profesionalización creciente del psicoanálisis en Alemania (especialmente a través de su reconocimiento por la seguridad social) y frente a las más diversas formas de su degradación en toda suerte de terapias, el juicio de Mitscherlich es severo: «Esta 
ciencia fundada por Freud ha permanecido extraña e inaccesible a los alemanes - no digo sólo a un gran número, a la mayor parte de los alemanes. No: a los alemanes sin másn. Por crispada que pueda parecer esta afirmación, toca ciertamente una verdad que no es el privilegio de ningún pueblo: la constante puesta en cuestión, individual y colectiva, que suscita el psicoanálisis no es tolerable más que hasta un cierto punto. Cuanto más vivas son sus heridas, tanto más se encierra la sociedad en sus ilusiones políticas o religiosas. Es particularmente triste constatar que los propios psicoanalistas llegan ellos mismos a contribuir a esta empresa oscurantista.

Cuando se descubre en la pluma de Rosenkötter el modo en el que se puede "encriptar" en la psique, incluso hasta en la tercera generación, la vergüenza social catastrófica que subraya el silencio de las generaciones anteriores, se llega a calibrar la importancia de la teoría desarrollada en Francia por Nicolas Abraham y Maria Torok acerca de las nociones de secreto, de fantasma, de criptonimia y de represión conservadora. Estamos igualmente en deuda con estos autores por haber mostrado cómo ciertas elaboraciones teóricas pueden edificarse sobre "encriptamientos" que conviene deconstruir. Para el discurso analítico, el ejercicio de su responsabilidad teórica y ético-política exige no sustraer a esta deconstrucción sus propias construcciones teóricas, sobre todo en lo que tienen de dogmático.

Tan marginada como Lacan en relación a la corriente dominante del psicoanálisis internacional (que se esfuerza en hacer regresar la teoría freudiana al cuadro de una teoría psicológica más general), Melanie Klein ha desarrollado una práctica y una conceptualización de esta práctica que se han extendido sobre todo en los países latinoamericanos. Pero éstas han influido también, de modo más insistente aún, en el pensamiento continental o norteamericano. Tomando su punto de partida en el estudio de las relaciones precoces entre la madre y el niño, la teoría kleiniana postula la existencia de una relación objetal real desde el nacimiento. Muy pronto, el niño tendría la capacidad de distinguir lo que viene "de dentro" y lo que viene "de fuera". M. Klein substituye la bipolaridad freudiana sujeto-objeto por la bipolaridad interior-exterior, que se desdobla en otra: la que opone bueno y malo. El artículo de Freud sobre La negación (1925) describía cómo se constituye el exterior (por la expulsión de lo "malo" percibido en el interior) y el interior (por la reapropiación de aquello que es percibido como bueno). Para M. Klein, la introyección podrá hacerse tanto con el objeto malo como con el objeto bueno. Lo mismo sucede con la proyección. Pero el objeto introyectado puede permanecer, tempo- 
ralmente o no, como un objeto extraño en el interior. Si para Freud se trataba de ver cómo se opera, en el interior, el desdoblamiento de la disyunción interior-exterior, se trataba también de pensar el origen mítico del pensamiento, la génesis del juicio (de los juicios de atribución y de existencia) y la manera en la que lo intelectual se separa en acto de lo afectivo. No es la afirmación lo que hace posible la función del juicio, sino la negación en cuanto ésta pone en juego lo simbólico.

La concepción kleiniana de la formación simbólica difiere de la de Freud -y de la de Lacan - puesto que la introyección del objeto malo va de la mano con la del objeto bueno. De ello resultará, ciertamente, la presencia interna de un objeto persecutorio que será responsable de las posiciones descritas como paranoide y depresiva (surgiendo la primera entre el nacimiento y la edad de tres meses y la segunda entre los tres y los seis meses), pero las ecuaciones simbólicas entre las partes del cuerpo de la madre y las partes del cuerpo del niño se erigirán como verdaderas piedras de toque para la formación simbólica. Esta no se articula, por otra parte, como en Lacan con la función del lenguaje. El acento se pone ante todo en los fantasmas inconscientes del niño referidos a su propio cuerpo y al de la madre y en la formación muy precoz de un superyo hecho de introyecciones, de proyecciones y de identificaciones proyectivas. Tal como lo ha descrito Melanie Klein en Envidia y gratitud lo que es fundamental en su concepción es el rasgo divisorio que marca al yo de modo constitutivo. A ella debemos haber sacado a la luz la extraordinaria facultad imaginativa del nino, su relación con la sexualidad infantil y con los fantasmas más arcaicos. Esto es lo que le habrá valido, de parte de Lacan, el ambiguo elogio de ser una "tripera de genio", lo que a la vez suponfa darle crédito en sus grandes intuiciones y poner en duda la racionalidad de su pensamiento. Será tarea de Wilfred R. Bion, un discípulo de Melanie Klein, formalizar, para hacerla transmisible, la concepción kleiniana del análisis.

Como Lacan, Melanie Klein habrá fundado una escuela. El signo de obediencia a un sistema de pensamiento se traduce en el campo de la práctica analítica por signos reconocibles. La referencia kleiniana prescribe un estilo de interpretación donde los fantasmas inconscientes del analizante son, a medida que van surgiendo, sacados a la luz y explicitados discursivamente en su relación actualizada con el analista, aunque este último se vea reducido así al papel que la transferencia en espejo, o la "identificación proyectiva», le hace jugar en la escena analítica. Estas construcciones interpretativas de los fantasmas nos han parecido siempre, a pesar del carácter bien concreto de sus enunciados, 
proporcionar, sobre todo, un marco teórico de legitimación, una ley o una racionalidad, para los pensamientos más profundamente entregados a la angustia. A este respecto, por muy arbitrario o autoritario que este marco pueda parecer, juega un papel estructurante. Pero no está libre del riesgo de control.

Hemos podido preguntarnos por las razones de la importante recepción que tuvo el pensamiento kleiniano en América del Sur, en las sociedades psicoanalíticas argentinas y brasileñas en particular. Sin seguir punto por punto la explicación propuesta por Carcamo, uno de los pioneros del psicoanálisis en Buenos Aires, según la cual esta difusión habría sido favorecida por el retorno a la madre, consecutivo al duelo que habría seguido la muerte de Freud, podemos evocar el favor del que disfruta lo imaginario en este continente y sus manifestaciones persistentes en la vida política y religiosa, así como la necesidad de anclar una cierta forma de proselitismo en una teoría fuertemente dogmática. La exportación del pensamiento lacaniano - centrado en un "retorno a Freud", concediendo su relectura y su reinterpretación una primacía a lo simbólico- conoce actualmente un destino comparable al anterior, con una fuerte implantación en estos mismos países, mientras que en Estados Unidos este pensamiento es acogido de modo favorable sobre todo en los departamentos de lenguas de la universidades, donde contribuye a la renovación de la crítica literaria. Pero, en este ámbito, "la deconstrucción" derridiana permanece en la avanzadilla de los trabajos más señalados.

Estas apreciaciones, muy sumarias, sobre la cultura del kleinismo y del lacanismo en los países latinoamericanos deberían naturalmente matizarse, habida cuenta a la vez de la proximidad con otras influencias y de la mezcla de estos pensamientos con problemáticas elaboradas por ciertos teóricos argentinos tales como Pichon-Rivière, Marie Langer o José Bleger.

En lo referente a la práctica a la que da lugar la teoría formalizada de Bion, que se ha extendido principalmente por San Francisco y Brasil (particularmente en Sâo Paulo), se puede observar, con la ayuda de los protocolos establecidos para las sesiones de control, que el acento recae sobre todo sobre los procesos de pensamiento que se ponen en juego en el hic et nunc de la sesión y sobre la toma de conciencia de la interacción de estos procesos entre el analizante y el analista. Ello conduce al analista a hacer frecuentes y largas intervenciones donde su función de holding (función de sostenimiento) se parece, aunque en términos diferentes, a la que describe Winnicot. La realidad sexual 
del inconsciente se haya, si no ausente, al menos relegada por entero a un segundo plano.

De ahí que nos aparezcan como muy diferentes las prácticas a las que da cobijo el nombre de psicoanálisis, en Europa o en América del Norte y del Sur, en las sociedades afiliadas a la Asociación Psicoanalítica Internacional (I.P.A.) o en los grupos, tan numerosos, que se han formado al margen de esta asociación. Estas prácticas se traducen por modos de escucha que varían según la atención se ponga ante todo en el lenguaje y en la cadena significante, en los fantasmas inconscientes y la angustia, en los procesos de pensamiento y su dominio sobre el otro; según el modo como se identifica la procedencia del mensaje que porta el discurso y el destinatario que se le atribuye; según se considere la interpretación como donadora de sentido o deshaciendo el «demasiado sentido"; según se conciba la letra/carta del mensaje como divisible o indivisible, interceptada por la interpretación o cumplimentando, gracias a ella, un trayecto que la devuelve al lugar donde falta...

Si se ha podido mostrar que la neutralidad del intérprete es un engaño, que su exclusión aparente participa de una identificación críptica y que las condiciones pulsionales, teóricas e histórico-institucionales determinan el contenido y el estilo de la interpretación, no por esto la implicación del analista en el desarrollo o en la conducción de un análisis, lo mismo que en la teoría que permite dar cuenta de ello, debe dejar de exponerse al despliegue de sus pliegues y al desanudamiento de sus nudos. Muchas técnicas de reparación se precipitan en esta disyuntiva donde la exigencia de un suplemento de análisis se sustituye tanto por una actitud "suficientemente buena» o una cualidad de empatía (Einfühlung, hacerse uno con el otro a través del sentimiento) como por una serie de explicaciones en las que el deseo del analista se desvela tanto mejor cuanto más enmascarado aparece.

El problema de la formalización de un método que se parece tanto a una téchne (un arte) como a una rigurosa lógica permanece si no irresuelto por completo, cuando menos muy abierto. La cuestión se complica, en el campo analítico, por la constante subversión a la que el inconsciente somete a la teoría. La relación del psicoanálisis con las ciencias en desarrollo (física, biología molecular, tecnologías) lo mismo que con la filosofía (y la filosofia de la ciencia) exige asimismo un reexamen periódico. Finalmente, tras el repliegue operado por el psicoanálisis en las condiciones de su práctica, en los países donde ha sido fuertemente medicalizado y considerado como una extensión de la psi- 
quiatría o de la psicología, se delinea una renovación de la reflexión sobre el modo en el que puede contribuir a repensar lo jurídico, lo social y lo político.

\section{Datos geográficos y debates epistemológicos}

Paralelamente a los desarrollos teóricos que acabamos de esbozar y a las diferentes prácticas que se refieren a ellos, los últimos decenios han visto una amplia implantación del psicoanálisis en el mundo, cómo su audiencia se ha acrecentado considerablemente y cómo se ha diversificado su reparto. La geografía no presenta ya en absoluto la misma configuración.

Si tomamos las cifras oficiales de la Asociación Psicoanalítica Internacional -las únicas publicadas-, constatamos en primer lugar un reparto de sus miembros entre Europa y América que se invierte tras la guerra. En efecto, de 307 miembros en 1931 (de los cuales un 22\% se encontraba entonces en Estados Unidos), se pasa en 1952 a 762 miembros de los cuales un $64 \%$ eran americanos. Esta situación debía conferir un estatuto particular a la Asociación Psicoanalítica Americana, miembro de la I.P.A., al permitirle reagrupar todas los sociedades regionales de los Estados Unidos disfrutando con ello de dos privilegios: una autonomía interna en lo concerniente a los criterios de formación y el reconocimiento exclusivo de la Asociación Americana en el seno de la I.P.A. Ahora bien, al haber restringido esta asociación siempre el acceso a la práctica analítica únicamente a los médicos, su monopolio debía ser contestado tarde o temprano. Lo que ocurrió en 1987 por una acción judicial emprendida contra la Asociación Americana e indirectamente contra la I.P.A. que era solidaria de aquélla, lo que supuso una grave crisis financiera para esta última y el descontento de las otras sociedades miembros (europeas y sudamericanas). La Asociación Americana fue obligada a renunciar a su monopolio, abriendo así el acceso a otras sociedades (particularmente de psicólogos) a la I.P.A., al juzgarse suficiente la formación dispensada por éstas. La Asociación Americana tomó, por otra parte, sus propias disposiciones para formar a quienes no eran médicos.

Mientras que los psicoanalistas americanos, que se habían quedado fuera de los cuadros de la I.P.A., aspiraban en su mayoría a formar parte de esta asociación internacional fuertemente burocratizada, en Francia asistimos a un movimiento inverso. Pertenecer a ella significa cada vez menos. La nueva generación se preocupa muy poco del reconocimiento por éste u otro de los nume- 
rosos grupos que se reparten la clientela de los adeptos o las influencias doctrinales. Es verdad que las instituciones analíticas se han visto sometidas estos últimos años a críticas muy serias. En Francia, hoy día, los analistas se consagran ante todo por sus trabajos y su reputación. Es decir, que el reconocimiento proviene, en buena parte, de instancias externas a las asociaciones. $\mathrm{La}$ situación es también particular en los países donde los maestros han sabido imponer su pensamiento. La Sociedad Británica representa a este respecto un caso excepcional, habiendo conseguido llegar a cohabitar kleinianos, freudianos (Anna Freud) y winnicottianos. En todos los demás sitios se han producido escisiones. En Francia, los analistas practicantes salidos de la escuela fundada por Lacan han llegado a ser más numerosos que los que pertenecen a las dos asociaciones afiliadas a la I.P.A., la Sociedad Psicoanalítica de París (S.P.P.) y la Asociación Psicoanalítica de Francia (A.P.F.). Lo mismo ocurre sin duda en América del Sur.

Para dar una idea del crecimiento del número de analistas en el mundo, basta con subrayar que en el transcurso de los tres decenios (1960-1980), sólo la I.P.A. ha crecido en un $900 \%$, pasando de 762 miembros en 1952 a cerca de 7000 en 1987. Teniendo en cuenta los analistas en formación, se estima que esta cifra llegará a 20000 a finales de siglo. Cifra que debe cuando menos doblarse, si consideramos los analistas no censados por esta asociación. Con todo, el crecimiento no sigue la misma curva en todos los paises. En los Estados Unidos se ha estabilizado y se sitúa en un $30 \%$ en el seno de la I.P.A. Los impulsos más espectaculares se producen hoy en Francia, en Alemania, en Italia, en Argentina y en Brasil. No es exagerado decir que toda la cultura argentina se halla en la actualidad muy influida por el psicoanálisis $y$, sobre todo, por las teorías kleiniana y lacaniana. Es cierto que los países que conocen un fuerte impulso en la demografía analítica son aquellos en los que el pensamiento de Lacan encuentra numerosos adeptos. En lo tocante a los países del Este, que desde Stalin fueron borrados de la geografía psicoanalítica (la I.P.A. cuenta administrativamente con tres regiones: América del Norte, América Latina y Europa y (¡el resto del mundo!), se abren de nuevo, después de medio siglo de forclusión del pensamiento freudiano, a la práctica analítica. La era de la Perestroika habrá contribuido también a este efecto, todavía inesperado en el coloquio de Tífilis sobre el inconsciente en 1979. Pero, sin duda, este último acontecimiento ya era un signo precursor.

Retomemos aquí, a guisa de breve conclusión para esta evocación geográfica, algunos aspectos de la cuestión epistemológica que plantea el psicoanáli- 
sis a los saberes constituidos y que se plantea a sí mismo en cuanto saber. Si el psicoanálisis se da, de un modo que sigue siendo aún problemático, una teoría del conocimiento que tiene su propia referencia en el estudio de los fenómenos psíquicos inconscientes, permanece también vinculado a unos referentes que aparentemente le son exteriores. Reconoce sus ascendentes literarios, filosóficos y científicos. El complejo de Edipo puede leerse lo mismo en Diderot que en Sófocles; el concepto de represión aparece en El mundo como voluntad y representación de Schopenhauer, el ello en Nietzsche, el «sujeto supuesto saber» en Platón. Pero el psicoanálisis no sólo toma prestados o se apropia los conceptos. Desestabiliza, en su campo de procedencia, las axiomáticas que éstos sostienen. De igual modo, la lectura de las obras y la filosofía del sujeto no son ya lo mismo desde que Freud elaborara su concepto de inconsciente. La lingüística saussuriana no ha quedado intacta con la concepción lacaniana del significante. Igualmente, el antiguo dualismo que regía las relaciones del alma y del cuerpo se ve enteramente puesto en cuestión por el concepto de pulsión, que asigna a lo corporal un vínculo con lo psíquico, un soporte somático a la actividad de pensamiento inconsciente. El cuerpo sabe con independencia de lo que el sujeto cree saber y el sujeto piensa allí donde no cree pensar. Esto no le impide al psicoanálisis esperar de la biología informaciones que le permitan completar o revisar su teoría de las pulsiones. Pondría en apuros, a su vez, a toda neurofisiología cerebral que recondujera la determinación del deseo únicamente a la variación de las tasas de endorfinas o a la regulación de la libido por opiáceos endógenos. La estructura físico-química de los sustratos biológicos no tiene una función causal eficiente. Es ante todo la solución encontrada por la auto-organización de lo viviente. La hipótesis de la génesis de los objetos mentales, y en particular de los conceptos, está considerada por la propia neurobiología como altamente especulativa. En cuanto a la pulsión, nos es conocida en el ámbito psicoanalítico esencialmente por la invariabilidad de su meta y el carácter indiferente de su objeto.

El debate actual sobre los fundamentos epistemológicos del psicoanálisis se traduce en términos muy diferentes según se sitúe en el contexto cultural americano o francés. En los Estados Unidos, se ha producido una viva controversia, que se ha podido seguir en la revista Psychoanalysis and Contemporary Thought, desde la aparición en 1984 del libro de Grünbaum, The Foundations of Psychoanalysis. Para este autor, el psicoanálisis debe responder a los criterios de una ciencia natural o a lo que De Boer llama una concepción empírico-analítica de la ciencia: sería un método que proporcionaría descripciones que tra- 
ducen la realidad en variables independientes y que encontraría las leyes que vinculan a estas variables entre sí. Contrariamente a Popper, Grünbaum considera que el psicoanálisis cumple en general con estas condiciones incluso si carece aún de "evidencia empírica». Luego, arremete con la concepción hermenéutica del psicoanálisis tal y como, según él, se habría hecho dominante en Estados Unidos a través de las lecturas de Jürgen Habermas y Paul Ricoeur. Es verdad que la teoría de la acción comunicativa de Habermas ha encontrado un amplio eco en los teóricos que se dedican a hacer del psicoanálisis una psicología científica, que conciben la relación analítica como una relación interpersonal o intersubjetiva y que entienden la interpretación como un mensaje que libera un significado. No por ello la referencia a las ciencias naturales es en sí más segura. Los discursos que son en este sentido "científicos" están también condicionados por el inconsciente y por formas de pensamiento difusas que se tomaron prestadas del lenguaje de una sociedad y de una época. Por otra parte, la posición adoptada por Ricoeur en artículos recientes ( $L a$ Question de la preuve dans les écrits de Freud, 1981) disuelve esta oposición entre hermenéutica y ciencia natural y considera que la metodología analítica implica un entendimiento tanto acausal como causal. Con todo, está permitido preguntarse sobre la posibilidad de descifrar la experiencia analítica, de parte a parte, como un texto sometido a fuerzas contradictorias cuyas lagunas de sentido podrían ser restituidas.

En Francia, la cuestión de la posición del psicoanálisis en relación a la ciencia ha revestido una gran intensidad a partir de Lacan. La obra de este último ofrece a este respecto, así como a otros, una trayectoria compleja. Si la lógica del significante y la doctrina de la verdad no rompen todo vínculo con la hermenéutica, la formalización algorítmica y los nudos borromeos tienden a fundar una cientificidad y una transmisibilidad propias del psicoanálisis. Que realmente puedan llegar a conseguirlo o que estas tentativas estén condenadas al fracaso es el objeto de un controvertido debate que ha tendido a radicalizarse estos últimos años. Pero es significativo que esto no se haga en los términos del positivismo lógico. El núcleo del problema es la división del sujeto y «la nosalida de la ciencia en su esfuerzo por suturarlo». Tratándose del mismo sujeto tanto para el psicoanálisis como para la "ciencia», ¿cómo incluirlo como sujeto de la enunciación en el objeto acerca del cual «él" pretende hablar? Una aporía semejante ha engendrado un estilo de discurso acerca del análisis que incluye en sus enunciados el esclarecimiento del inconsciente del sujeto parlante, sin que esto implique que sea transmisible. Para François Roustang, el 
objetivo perseguido por Lacan de fundar este discurso como ciencia oscilaría entre «el seguimiento riguroso y la digresión ininterrumpida». La equivocidad de este discurso ¿conduce a un callejón sin salida o es signo de una sorprendente fecundidad?

Un discurso singular debe poder ser confrontado a las generalizaciones de la teoría sin perder por ello su singularidad. Su interpretación debe poder responder a los criterios de verificación siendo, no obstante, cada vez inesperada. Cada análisis redescubre con sorpresa lo que ya habrá sabido siempre. Finalmente, la teoría clínica y la metapsicología no tienen el mismo rangoo. $\mathrm{Si}$ la primera se funda en fenómenos psíquicos inconscientes "objetivados", la segunda comporta hipótesis por verificar y especulaciones sujetas a revisión. Sea cual sea la certeza del físico acerca del color del sol o sobre la luz que éste difunde, siempre nos estará permitido hablar de "sol negro" y de su "oscura claridad". 